\title{
Laparoscopic hepatectomy versus open hepatectomy for colorectal cancer liver metastases: comparative study with propensity score matching
}

\author{
Xavier Untereiner ${ }^{1}$, Audrey Cagniet ${ }^{2}$, Riccardo Memeo ${ }^{1,3}$, Stylianos Tzedakis $^{1}$, Tullio Piardi ${ }^{2}$, \\ François Severac ${ }^{4}$, Didier Mutter ${ }^{1,3}$, Reza Kianmanesh ${ }^{2}$, Jacques Marescaux ${ }^{1,3}$, Daniele Sommacale ${ }^{2}$, \\ Patrick Pessaux ${ }^{1,3}$
}

${ }^{1}$ Department of Digestive and Liver Diseases (Pôle Hépatodigestif), Nouvel Hôpital Civil, Hôpitaux Universitaires de Strasbourg, Université de Strasbourg, Strasbourg, France; ${ }^{2}$ Department of General, Digestive, and Endocrine Surgery, Hôpital Robert Debré, Centre Hospitalier Universitaire de Reims, Université de Reims Champagne-Ardenne, Reims, France; ${ }^{3}$ Research Institute Against Digestive Cancer-Institut de Recherche sur les Cancers de l'Appareil Digestif (IRCAD)-Institut Hospitalo-Universitaire de Strasbourg (IHU Mix-Surg), Strasbourg, France; ${ }^{4}$ Biostatistics and Computer Science Medical Laboratory, Faculty of Medicine, Hôpitaux Universitaires de Strasbourg, Strasbourg, France

Contributions: (I) Conception and design: D Sommacale, P Pessaux, T Piardi, R Memeo; (II) Administrative support: J Marescaux, P Pessaux; (III) Provision of study materials or patients: R Kianmanesh, P Pessaux, J Marescaux, D Mutter, R Memeo, T Piardi, D Sommacale; (IV) Collection and assembly of data: X Untereiner, A Cagniet, R Memeo, S Tzedakis, F Severac; (V) Data analysis and interpretation: X Untereiner, A Cagniet, R Memeo, S Tzedakis, F Severac; (VI) Manuscript writing: All authors; (VII) Final approval of manuscript: All authors.

Correspondence to: Professor Patrick Pessaux, MD, PhD. Head of the Hepatobiliary and Pancreatic Surgical Unit, Nouvel Hôpital Civil (NHC), 1, place de l’hôpital, 67091 Strasbourg, France. Email: patrick.pessaux@chru-strasbourg.fr.

Background: The objective of this study was to compare the results of laparoscopic hepatectomy with those of open hepatectomy for colorectal cancer liver metastases (CCLM) using a propensity score matching (PSM) in two university hospital settings.

Methods: A patient in the laparoscopic approach (LA) surgery group was randomly matched with another patient in the open approach (OA) group using a 1:1 allocated ratio with the nearest estimated propensity score. No patients of the LA group were excluded for the matching. Matching criteria included age, gender, body mass index (BMI), American society anesthesiologists score, potential co-morbidities, hepatopathies, synchronous or metachronous lesions, size and number of CCLM, preoperative chemotherapy, minor or major liver resections. Intraoperative, postoperative data, and survival were compared in both groups.

Results: From January 2012 to January 2015, a total of 242 hepatectomies were consecutively performed, of which 119 for CCLM, namely 101 in the OA group (84.9\%) and 18 in the LA group (15.1\%). The conversion rate was $5.6 \%(\mathrm{n}=1)$. The mortality rate was $1 \%$ in the OA group and $0 \%$ in the LA group. Prior to PSM, there was a statistically significant difference favorable to the LA group regarding operative time, blood loss, length of hospital stay and the rate of medical complications. After PSM, there was no difference regarding operative time or length of hospital stay. However, there was a trend towards less blood loss $(\mathrm{P}=0.066)$ and fewer medical complications (44.4\% vs.16.7\%, $\mathrm{P}=0.07)$. The $\mathrm{R} 0$ resection rate was $94.4 \%$ $(\mathrm{n}=17)$ in the two groups. In addition, there was no difference regarding overall survival $(\mathrm{P}=0.358)$ and recurrence-free survival [HR =0.99 (0.1-12.7); $\mathrm{P}=0.99]$.

Conclusions: Laparoscopic liver resections for CCLM seem to yield short- and long-term results, which are similar to open hepatectomies, and could well be considered an alternative to open surgery and become the gold standard in carefully selected patients.

Keywords: Laparoscopy; hepatectomy; colorectal metastases; outcomes; propensy score

Submitted Jul 08, 2015. Accepted for publication Sep 24, 2015.

doi: $10.21037 / \mathrm{hbsn} .2015 .12 .06$

View this article at: http://dx.doi.org/10.21037/hbsn.2015.12.06 


\section{Introduction}

In 2012, the incidence of colorectal cancer is estimated at 447,000 new cases and 215,000 deaths (1). It is the third most common type of cancer worldwide $(2,3)$. Liver resection is the only curative treatment for colorectal cancer liver metastases (CCLM) with primary tumor resection associated or not with perioperative chemotherapy (4-6) allowing for a 5 -year survival ranging from $30 \%$ to $58 \%$ $(7,8)$. Over the past 20 years, the mortality rate of colorectal cancer at a metastatic stage dropped with the advances made in terms of management, i.e., early diagnosis and improved therapeutic modalities. Indeed, chemotherapy and the advent of targeted therapies have allowed to turn initially non-resectable tumor patients into resectable patients in combination with an improved prognosis, particularly for patients responding to treatments $(9,10)$, and the same is true for iterative resections (11). In addition, recent data demonstrated that surgical treatments are better than local radiofrequency ablations (12). Currently, there are two surgical approaches, namely the open approach (OA) and the laparoscopic approach (LA). The LA in liver pathologies remains limited contrarily to abdominal surgery. It is mainly due to the technical complexity of interventions, the lack of appropriate instrumentation, the risk of gas embolism, of uncontrolled bleeding, the fear of carcinologic limitations and of tumor dissemination. Several studies have demonstrated that the LA is also safe in carefully selected patients (13-15) with better short- and mid-term results (16-20).

Indications for laparoscopic hepatectomies were defined during the first international consensus conference held in Louisville, USA (21) in 2008 and revised in Morioka (22) in 2014. This approach is used for patients selected with the following criteria: tumor localization, size of lesions, liver function, and the experience of the surgical team. Although it was demonstrated that the LA elicits several advantages such as less postoperative pain, quicker restoration of bowel habits, less respiratory and parietal morbidity, improved quality of life, and reduced hospital stay (23-25), this approach is currently limited to mere liver resections, which are either peripheral or superficial. Very few large and complex resections have been described $(26,27)$ and few series report the specific results of laparoscopic colorectal cancer liver resections $(28,29)$. The objective of this study was to compare the morbidity and the mortality of laparoscopic hepatectomy with open hepatectomy for CCLM using propensity score matching (PSM) in two University hospital settings.

\section{Methods}

From January 2012 to January 2015, data of all patients who underwent hepatectomy in two University hospital settings were collected. All patients who required liver surgery for synchronous or metachronous CCLM with histological evidence were included in this database. The LA was selected by each team depending on CCLM size and localization during an interdisciplinary meeting. Both teams performed laparoscopic liver resection. All surgical interventions were performed by expert physicians in laparoscopic and open surgery. In all cases, the objective of surgical treatment was to perform a complete macroscopic CCLM resection with a remnant liver volume $>40 \%$ of the total liver volume (30). Operative techniques used for laparoscopy and open surgery have already been described (31-34). Intraoperatively, a Doppler ultrasound was routinely performed in order to confirm the number and the size of lesions and to search for occult lesions, to assess vascular relationships, and to determine whether minor or major surgeries are required.

\section{Perioperative and postoperative parameters}

The following variables were analyzed: type of liver resections (segmentectomies, bisegmentectomies, wedge resections, etc.), use of radiofrequency, number of resected segments, operative time, number of clampings, duration and type of clamping, rate of conversion, blood loss, number of transfusions, length of hospital stay, rate of R0 resection margins. All postoperative complications were indexed, namely respiratory (atelectasis, pneumopathy), cardiovascular (cardiac rhythm disorders, ischemia, cardiac decompression, hypertension), renal (acute renal failure, pyelonephritis, cystitis), parietal infections, deep collections, bleeding, biliary fistulas, liver failure, and ascites. After surgery, all patients were followed up every three months during the first year, and then every 6 months with blood tests (including the ACE test) and an abdominopelvic CT-scan.

\section{Definitions}

Liver segmentation was defined according to the Couinaud classification (35). Liver resections were defined according to the Brisbane classification in 2000 (36), using the following definitions: hepatectomy was defined as major when three or more segments were removed. Other hepatectomies, which were limited, were performed 
on two segments or less (standard segmentectomy, bisegmentectomy or sub-segmentectomy).

Complications were classified according to the ClavienDindo classification (37). Complications were indexed as medical complications, including respiratory complications (atelectasis, pneumopathy), cardiovascular complications (including cardiac rhythm disorders, ischemia, cardiac decompression, hypertension), renal complications (acute renal failure, pyelonephritis, cystitis), parietal infections, deep collections, bleeding, biliary fistulas, liver failure, ascites, and as surgical complications including drainage of deep collections, ascites, biliary fistulas, bleeding, eviscerations, parietal collections and acute ischemia.

\section{Propensity score matching (PSM)}

All demographic and preoperative characteristics of patients who were operated on laparoscopically were compared using a univariate analysis in order to assess comparability of both groups. A propensity score was calculated to take into account and limit selection biases, and to reduce confusion between both groups. This method allows to compare the effects of the two procedures (LA $v s$. OA) taking into account the variables impacting the choice of the intervention. The propensity score was estimated using logistic regression which included the following variables: age, gender, comorbidity, American Society of Anesthesiologists (ASA) score, synchronous or metachronous tumors, neoadjuvant treatment, total number of nodules, and resection type. The choice of such variables was based on the univariate analysis results and/or on the known influence of specific factors in a determined type of intervention. A propensity score matching (PSM) ratio 1:1 was achieved based on the "nearest neighbor" method. After PSM, both groups were compared with regards to their initial characteristics in order to re-evaluate their comparability. Finally, matching groups were compared with regards to the different variables at stake in the study.

\section{Recurrence and survival}

The study began on the day of the first liver resection. Death causes were recorded. All deaths and colorectal cancer recurrences were evaluated in order to calculate the survival rate with and without recurrence. The survival rate was evaluated using Fong's criteria (5) (lymph node involvement, synchronous or metachronous lesions, serum carcinoembryonic antigen (CEA) levels $>200$, size and number of nodes).

The analysis was performed at least 6 months postoperatively in each patient.

\section{Statistical analysis}

Asymmetric quantitative variables were reported in the form of medians combined with first and third quartiles after evaluation of their distribution. Qualitative variables were reported in the form of numbers and percentages. The comparison of quantitative variables was performed using a Mann-Whitney test. The comparison of qualitative variables was performed using either the Chi test ${ }^{2}$ or Fisher's exact test according to the numbers obtained. Overall survival and recurrence-free survival were analyzed according to the Kaplan-Meier estimate. Survival curves were compared using the $\log$ rank test. A $\mathrm{P}$ value $<0.05$ was considered significant. All evaluations were achieved by means of the R 3.2.0 software (R Core Team, R Foundation for Statistical Computing, Vienna, Austria).

\section{Results}

\section{Population and short-term results before matching}

From January 2012 to January 2015, a total of 242 consecutive hepatectomies were performed, including 119 hepatectomies for CCLM, including 101 resections performed using laparotomy (84.9\%), and 18 performed laparoscopically (15.1\%), including 1 robot-assisted laparoscopy using the da Vinci ${ }^{\mathrm{TM}}$ robot (da Vinci Si ${ }^{\mathrm{TM}}$ Robotic Surgical System; Intuitive Surgical Inc, Sunnyvale, CA, USA).

Regarding patient characteristics, the two groups were similar, except for gender ratio, the presence of a comorbidity $(67.3 \%$ of patients in the OA group and $38.9 \%$ of patients in the LA group, $\mathrm{P}=0.021$ ) and the presence of a liver disease with a fatty liver in the OA group (4\% in the OA group and $0 \%$ in the LA group, $\mathrm{P}=0.011$ ) (Table 1). In addition, statistics revealed fewer lesions in the LA group as compared to the OA group [3.0 (1.0-5.0) vs. 1.0 (1.0-2.0); $\mathrm{P}<0.001]$, and more major liver diseases in the OA group as compared to the LA group (41.6\% vs. $11.1 \%$ in; $\mathrm{P}=0.014$ ) (Table 1). The detailed procedures are summarized in Table 2 , where one can see that a smaller segment was resected in the LA group (median of 1 vs. $2 ; \mathrm{P}=0.003$ ), and that more segmentectomies were performed in the LA group $38.9 \%$ vs. $7.9 \% ; \mathrm{P}=0.002)$. Statistically, there was a significant difference in favor of the LA group regarding operative 


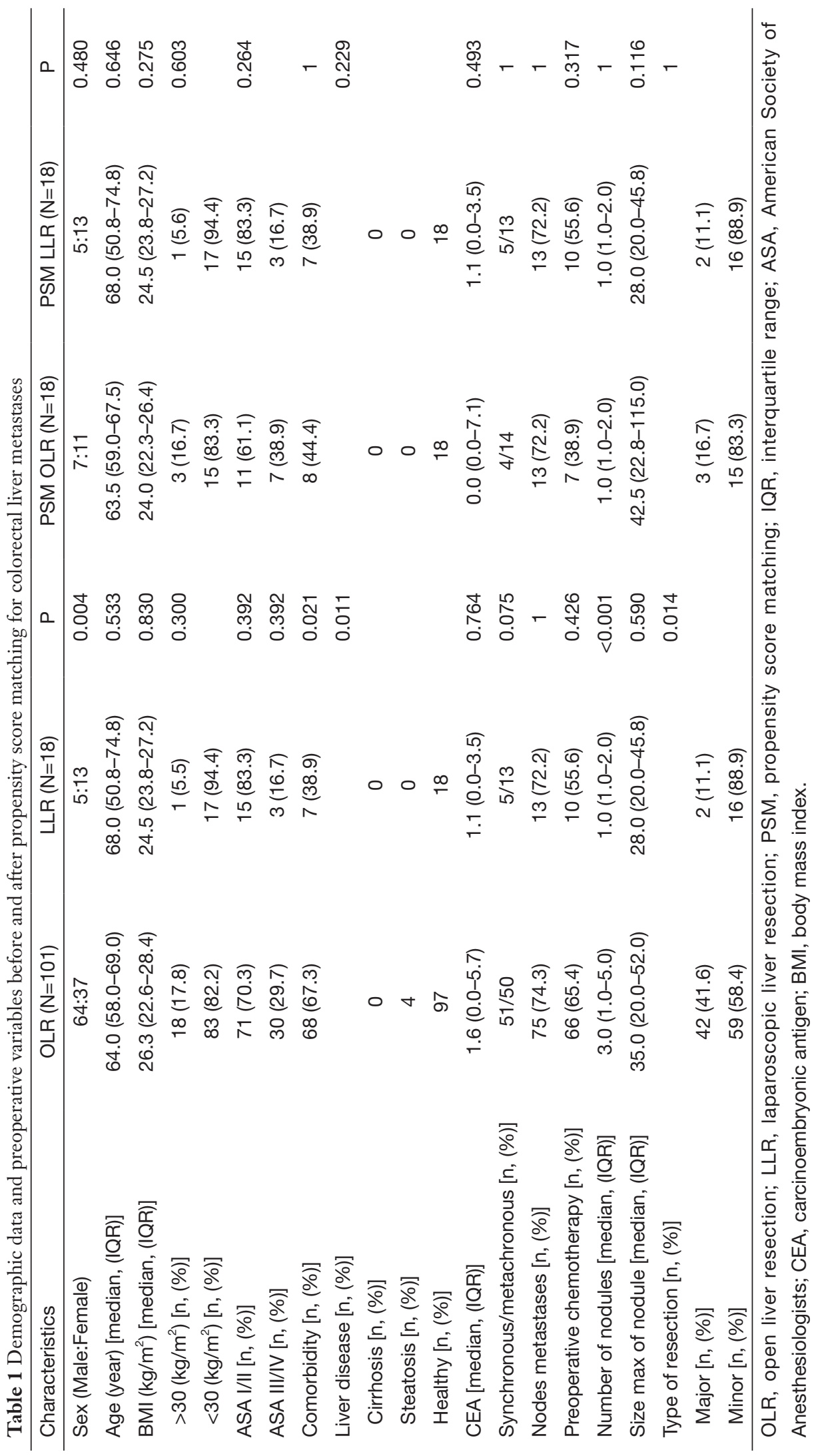




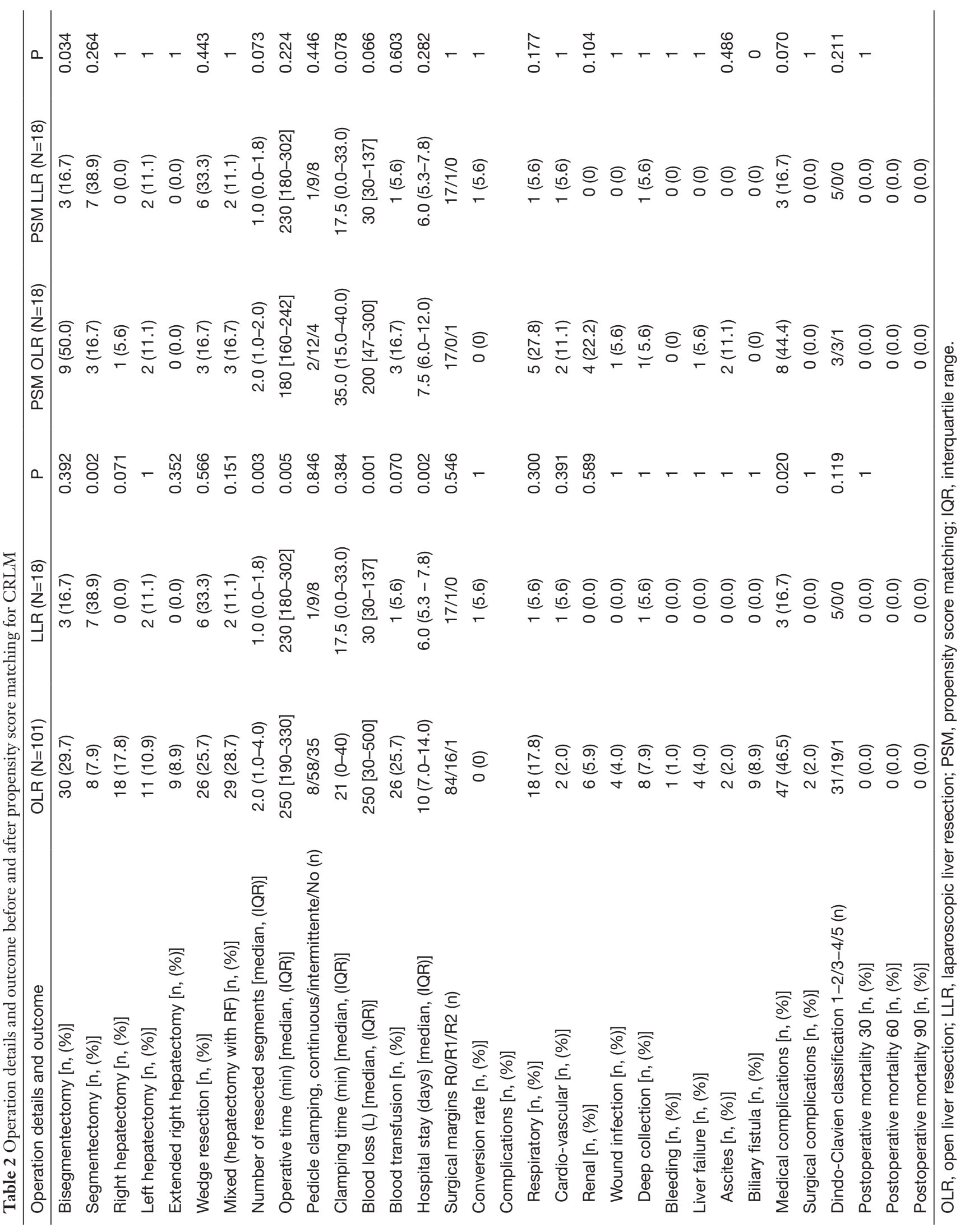




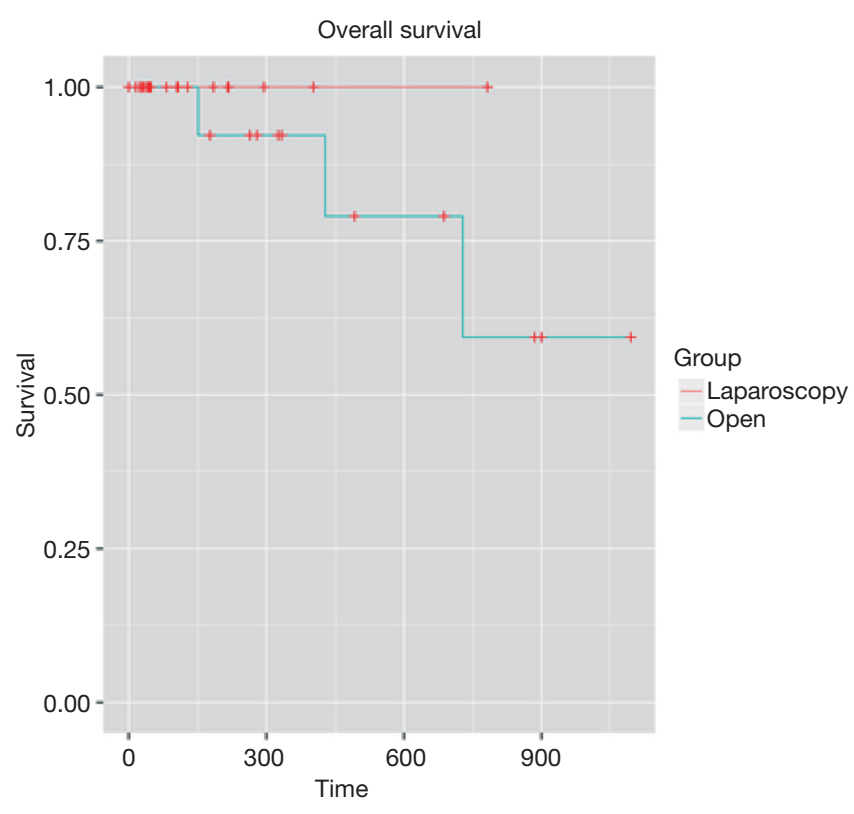

Figure 1 Overall survival according to Kaplan-Meier.

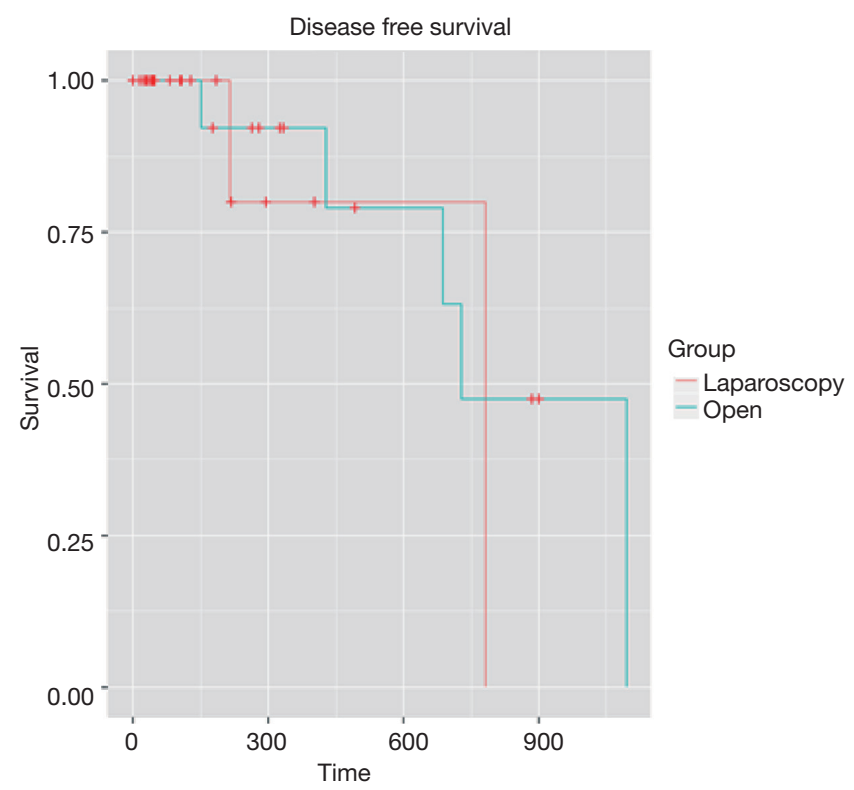

Figure 2 Disease-free survival according to the Cox model.

time, blood loss, and length of hospital stay (Table 2). The conversion rate was $5.6 \%(\mathrm{n}=1)$, given the presence of numerous pedicular adenopathies which required an extensive treatment.

The mortality rate was $1 \%$ in the OA group and $0 \%$ in the LA group. The cause of death was multiple organ failure after bisegmentectomy VII-VIII in an ASA 2 patient who had undergone three preoperative chemotherapies (administration of FOLFOX).

There were no differences in terms of postoperative complications, except for the rate of medical complications, which was reduced in the LA group (16\% vs. $46.7 \%$; $\mathrm{P}=0.002)$ (Table 2).

\section{Population and short-term results after matching and PSM}

Once the propensity score had been used, 18 patients in the LA group were matched with 18 patients in the OA group. Both groups had similar characteristics. They were at the same stage of the disease, and the surface covered by the procedure was similar in both groups (Table 2), although more bisegmentectomies were performed in the OA group ( $50 \%$ vs. $16.7 \% ; \mathrm{P}=0.034)$.

There were no differences in terms of operative time and length of hospital stay. However, blood loss was reduced, $(\mathrm{P}=0.066)$, and there were fewer medical complications ( $44.4 \%$ vs. $16.7 \%, \mathrm{P}=0.07$ ). Resection rate $\mathrm{R} 0$ was $94.4 \%$ $(\mathrm{n}=17)$ in both groups.

\section{Overall survival and disease-free survival}

Mean follow-up was 5.4 months [IQR (1.43-11.64)]. Even if the mean follow-up was relatively short, preliminary results are encouraging with similar overall survival rates were observed for two groups at 1 and 3 years: $100 \%, 100 \%$ for the LA group, respectively, and $94.4 \%$ and $83.3 \%$ for the OA group, respectively $(\mathrm{P}=0.358)$ (Figure 1$)$. The 1 - and 3 -year disease-free survival rates were $94.4 \%$ and $88.9 \%$ for the LA group, respectively, and $94.4 \%$ and $77.8 \%$ for the OA group $(\mathrm{P}=0.534)$ (Figure 2). Disease-free survival was calculated according to a Cox proportional hazard model, taking Fong's criteria (5) into consideration. There were no significant differences in terms of recurrence-free survival $[\mathrm{HR}=0.99$ (0.1-12.7); $\mathrm{P}=0.99]$. The median time after liver resection was 6 months.

\section{Discussion}

The objective of this study was to compare short-term results of the laparoscopic and OA for hepatectomies performed for CCLM, using a propensity score. There was an indication selection with more limited and minor resections in the laparoscopic group, with fewer resected lesions. Within this population, there was a decrease in blood loss, hospital stay, postoperative complications in the 
laparoscopic group, and an absence of long-term difference on survival and recurrence. After a PSM on essential factors which influence morbidity and mortality, there were no longer any differences between the two groups with a tendency towards a blood loss reduction and fewer medical complications. A Cox test was performed and there was no difference in terms of survival or recurrence, according to the main prognostic criteria.

In the literature, several authors have reported good results with hepatic metastases resection using an $\mathrm{OA}$, with a 5 -year survival rate of over $50 \%(38,39)$. Given these good results, the LA must provide equivalent short-term results (morbidity and mortality), but more importantly in terms of oncological results at 5 years. Special concerns with regards to oncological relevance of laparoscopy generally speaking, include recurrences at port entry sites, the trophic effect of the pneumoperitoneum on cancer cells, the inability to properly inspect the peritoneal cavity, and the lack of tactile feedback during liver inspection. This accounts for the fact that the LA to the liver is not as widely used as other abdominal surgery approaches.

The choice of a LA was based on the location, the number and the size of CCLM after a discussion in a multidisciplinary meeting. Exclusion criteria for laparoscopy were the need to perform a vascular procedure or a biliary reconstruction. Generally speaking, we preferred to use open resections only for lesions located in the center of the liver, for those located proximally to hepatic veins, and for lesions which are difficult to access when using laparoscopy (upper and lower segment). We used the criteria described in the literature $(21,22)$ regarding the feasibility of hepatic resections using a LA, namely: the superficial location of the lesion (segments II to VI), the relationship with vessels as well as a size of less than $5 \mathrm{~cm}$.

This accounts for the fact that more minor and limited resections were performed laparoscopically. This observation led to the implementation of a PSM according to the main factors which influence morbidity and mortality, in order to eliminate this selection bias. Left lateral sectionectomy was most often performed laparoscopically, as this seems to be the most adapted approach due to the fact that the liver is not very thick, due to the possibility of a resection without hilar dissection, and to the fact that the division of the left hepatic vein and of the portal pedicles of segments II and III are easy to perform. In contrast, right hepatectomies were mainly performed using an OA due to technical difficulty and also because this series takes our learning curve into account.
Cherqui $(26,40)$ insisted that patient selection for laparoscopic hepatectomies should be very strict and based on the size of lesions and their favorable topography. It was mandatory that the LA did not modify operative procedures used for open surgery, hepatectomy indications had to be respected, as did carcinological rules for malignant tumors. According to this author, in 2006, the indication for hepatectomy using a LA was the presence of CCLM, or indications were validated for open surgery. Voluminous tumors greater than $5 \mathrm{~cm}$ in size, with a close relationship with suprahepatic veins and/or the inferior vena cava, must no longer be absolute contraindications for laparoscopy $(31,41)$, but the approach should be chosen on a case-bycase basis, evaluating individual risks and a strategy to spare the liver parenchyma (42).

In addition, portal clamping was applied regardless of the type of hepatic resection. The hepatic pedicle is routinely controlled at the beginning of the intervention in order to perform a pedicular clamping if required, and this occurred in $55.6 \%$ of cases in our series. We mainly privileged intermittent clamping (20 minutes with 10-minute phases of reperfusion, except in cirrhotic patients in which clamping would not exceed 15 minutes) due to a superior hepatic tolerance, especially in cirrhotic patients (43-45), as well as a better short- and long-term prognosis (46). We reported one permanent clamping, but this corresponds to very superficial resections. Additionally, laparoscopic clamping, which is associated with pneumoperitoneum pressure, allows to decrease bleeding and almost completely eliminates the use of continuous aspiration, which is not feasible.

In our study, benefits of the LA were not significantly demonstrated. However with PSM, intraoperative bleeding tended to decrease (30vs. $200 \mathrm{~mL}, \mathrm{P}=0.066$ ), as did hospital stay with a median duration of 6 vs. 8 days $(\mathrm{P}=0.282)$, which came at the cost of a longer operative time (230 vs. 180 minutes, $\mathrm{P}=0.224)$. The same goes for postoperative outcomes, which appeared to be less eventful with reduced medical complications ( $16.7 \%$ vs. $44.4 \%, \mathrm{P}=0.07)$. The absence of statistically significant results is probably due to the small number of patients in this series, and consequently to the lack of statistical power. As for surgical complications, laparoscopy does not provide any real benefits. Cannon et al. reported similar results in their series $(23 \%$ vs. $50 \%$, $\mathrm{P}=0.004)$ (47).

In addition, the conversion rate described in the literature is in the $5-15 \%$ range $(48-50)$. The two main reasons for that were: (I) a technical problem linked to exposure with 
a risk of tumoral rupture dissemination for fragile lesions or a doubt concerning a sufficient resection margin; (II) an uncontrolled bleeding. In our series, we report a conversion rate of $5.6 \%$, the main reason of which was the presence of pedicular adenopathies requiring a laparoscopic curettage which was difficult to perform laparoscopically.

Given the multiple arguments in favor of laparoscopy for hepatic surgery, it is unlikely that a laparoscopic versus open hepatic resection controlled randomized prospective study would be performed. Indeed, considerable practical obstacles should be taken into account for a randomized trial. However, at least two clinical trials (NCT01516710 and NCT01441856) are under way and we await the results. An important obstacle to the development of a randomized study is the reluctance of patients as far as being randomized to an open technique is concerned, as existing data suggests that laparoscopic resection is safe with less eventful outcomes and equivalent oncological outcomes.

Therefore, most comparisons are limited to observational studies which are potentially biased by a selection bias. The strength of this study is the use of the matching technique based on the propensity score, as it simulates randomization and eliminates confusion caused by variables used to create the study groups. By using this test, the effect of the resection's treatment using laparoscopy as compared to an $\mathrm{OA}$ is estimated more precisely in this study (51-53). An important limitation to this study is its relatively small sample size, with only 18 patients who benefited from a laparoscopic resection. Despite such inconvenients, our work suggests that laparoscopic resection for CCLM are an efficient and beneficial alternative in patients who have been carefully selected.

In addition, the negative resection margin rate (R0) in this series is similar in both groups (94.4\%), which demonstrates that the anatomical dissection of the intrahepatic tumor can be obtained during laparoscopic resection. Laparoscopic ultrasonography is a key element to obtaining such results. The possibility to perform an intraoperative ultrasonography has been mentioned by the consensus of international experts in hepatic surgery as being an indispensable preliminary exam before any liver resection, regardless of the technique used $(21,22)$. Authors have no reason to believe that there are intrinsic factors to the LA which would allow to obtain a greater negative margin rate in comparison to the $\mathrm{OA}$, as the objective is to obtain a result just as good. Additionally, recurrencefree survival and survival with recurrence are equivalent in both groups of this study, and the results have already been reported in the literature $(16,49,54,55)$. These results allow to come forward with a laparoscopic resection of CCLM. The results were obtained in our series as well as in series published by experimented surgeons, in the field of hepatic surgery as well as in laparoscopy, and consequently these results can only be extrapolated with caution in all centers.

\section{Conclusions}

Laparoscopic liver resections for CCLM seem to produce the same results as the OA in the short- and long-term. It could be considered as an alternative to open surgery and become the gold standard for carefully selected patients.

\section{Acknowledgements}

Authors are grateful to Mathilde Raux-Defossez, Christopher Burel, and Guy Temporal for their valuable translation.

\section{Footnote}

Conflicts of Interest: The authors have no conflicts of interest to declare.

\section{References}

1. Ferlay J, Steliarova-Foucher E, Lortet-Tieulent J, et al. Cancer incidence and mortality patterns in Europe: estimates for 40 countries in 2012. Eur J Cancer 2013;49:1374-403.

2. Forman D, Bray F, Brewster DH, et al. Cancer Incidence in five Continents, Volume X. Lyon, France: IARC Cancerbase, 2013.

3. Jemal A, Bray F, Center MM, et al. Global cancer statistics. CA Cancer J Clin 2011;61:69-90.

4. Adam R, Delvart V, Pascal G, et al. Rescue surgery for unresectable colorectal liver metastases downstaged by chemotherapy: a model to predict long-term survival. Ann Surg 2004;240:644-57; discussion 657-8.

5. Fong Y, Fortner J, Sun RL, et al. Clinical score for predicting recurrence after hepatic resection for metastatic colorectal cancer: analysis of 1001 consecutive cases. Ann Surg 1999;230:309-18; discussion 318-21.

6. Curley SA. Outcomes after surgical treatment of colorectal cancer liver metastases. Semin Oncol 2005;32:S109-11.

7. Pawlik TM, Scoggins CR, Zorzi D, et al. Effect of surgical margin status on survival and site of recurrence after hepatic resection for colorectal metastases. Ann Surg 
2005;241:715-22, discussion 722-4.

8. Nordlinger B, Sorbye H, Glimelius B, et al. Perioperative FOLFOX4 chemotherapy and surgery versus surgery alone for resectable liver metastases from colorectal cancer (EORTC 40983): long-term results of a randomised, controlled, phase 3 trial. Lancet Oncol 2013;14:1208-15.

9. Adam R, De Gramont A, Figueras J, et al. The oncosurgery approach to managing liver metastases from colorectal cancer: a multidisciplinary international consensus. Oncologist 2012;17:1225-39.

10. Beppu T, Miyamoto Y, Sakamoto Y, et al. Chemotherapy and targeted therapy for patients with initially unresectable colorectal liver metastases, focusing on conversion hepatectomy and long-term survival. Ann Surg Oncol 2014;21 Suppl 3:S405-13

11. Wicherts DA, de Haas RJ, Salloum C, et al. Repeat hepatectomy for recurrent colorectal metastases. Br J Surg 2013;100:808-18.

12. Schiffman SC, Bower M, Brown RE, et al. Hepatectomy is superior to thermal ablation for patients with a solitary colorectal liver metastasis. J Gastrointest Surg 2010;14:1881-6; discussion 1886-7.

13. Qiu J, Chen S, Pankaj P, et al. Laparoscopic hepatectomy for hepatic colorectal metastases -- a retrospective comparative cohort analysis and literature review. PLoS One 2013;8:e60153.

14. Wei M, He Y, Wang J, et al. Laparoscopic versus open hepatectomy with or without synchronous colectomy for colorectal liver metastasis: a meta-analysis. PLoS One 2014;9:e87461.

15. Zhou Y, Xiao Y, Wu L, et al. Laparoscopic liver resection as a safe and efficacious alternative to open resection for colorectal liver metastasis: a meta-analysis. BMC Surg $2013 ; 13: 44$.

16. Mala T, Edwin B, Gladhaug I, et al. A comparative study of the short-term outcome following open and laparoscopic liver resection of colorectal metastases. Surg Endosc 2002;16:1059-63.

17. Carswell KA, Sagias FG, Murgatroyd B, et al. Laparoscopic versus open left lateral segmentectomy. BMC Surg 2009;9:14.

18. Abu Hilal M, Di Fabio F, Teng MJ, et al. Single-centre comparative study of laparoscopic versus open right hepatectomy. J Gastrointest Surg 2011;15:818-23.

19. Guerron AD, Aliyev S, Agcaoglu O, et al. Laparoscopic versus open resection of colorectal liver metastasis. Surg Endosc 2013;27:1138-43.

20. Morino M, Morra I, Rosso E, et al. Laparoscopic vs open hepatic resection: a comparative study. Surg Endosc 2003;17:1914-8.

21. Buell JF, Cherqui D, Geller DA, et al. The international position on laparoscopic liver surgery: The Louisville Statement, 2008. Ann Surg 2009;250:825-30.

22. Wakabayashi G, Cherqui D, Geller DA, et al. Recommendations for laparoscopic liver resection: a report from the second international consensus conference held in Morioka. Ann Surg 2015;261:619-29.

23. Koffron AJ, Auffenberg G, Kung R, et al. Evaluation of 300 minimally invasive liver resections at a single institution: less is more. Ann Surg 2007;246:385-92; discussion 392-4.

24. Simillis C, Constantinides VA, Tekkis PP, et al. Laparoscopic versus open hepatic resections for benign and malignant neoplasms--a meta-analysis. Surgery 2007;141:203-11.

25. Tranchart H, Dagher I. Laparoscopic liver resection: a review. J Visc Surg 2014;151:107-15.

26. Cherqui D, Chouillard E, Laurent A, et al. Hépatectomies par abord cœlioscopique. Encycl Méd Chir - Techniques Chirurgicales - Appareil digestif 2006;40-768.

27. Are C, Fong Y, Geller DA. Laparoscopic liver resections. Adv Surg 2005;39:57-75.

28. de'Angelis N, Eshkenazy R, Brunetti F, et al. Laparoscopic versus open resection for colorectal liver metastases: a single-center study with propensity score analysis. J Laparoendosc Adv Surg Tech A 2015;25:12-20.

29. Lin Q, Ye Q, Zhu D, et al. Comparison of minimally invasive and open colorectal resections for patients undergoing simultaneous R0 resection for liver metastases: a propensity score analysis. Int J Colorectal Dis 2015;30:385-95.

30. Truant S, Oberlin O, Sergent G, et al. Remnant liver volume to body weight ratio $>$ or $=0.5 \%$ : A new cut-off to estimate postoperative risks after extended resection in noncirrhotic liver. J Am Coll Surg 2007;204:22-33.

31. Bryant R, Laurent A, Tayar C, et al. Laparoscopic liver resection-understanding its role in current practice: the Henri Mondor Hospital experience. Ann Surg 2009;250:103-11.

32. Cherqui D, Malassagne B, Colau PI, et al. Hepatic vascular exclusion with preservation of the caval flow for liver resections. Ann Surg 1999;230:24-30.

33. de'Angelis N, Memeo R, Calderaro J, et al. Open and laparoscopic resection of hepatocellular adenoma: trends over 23 years at a specialist hepatobiliary unit. HPB (Oxford) 2014;16:783-8. 
34. Memeo R, de'Angelis N, Compagnon P, et al. Laparoscopic vs. open liver resection for hepatocellular carcinoma of cirrhotic liver: a case-control study. World J Surg 2014;38:2919-26.

35. Couinaud C. Definition of hepatic anatomical regions and their value during hepatectomy (author's transl). Chirurgie 1980;106:103-8.

36. Strasberg SM, Phillips C. Use and dissemination of the brisbane 2000 nomenclature of liver anatomy and resections. Ann Surg 2013;257:377-82.

37. Clavien PA, Barkun J, de Oliveira ML, et al. The ClavienDindo classification of surgical complications: five-year experience. Ann Surg 2009;250:187-96.

38. House MG, Ito H, Gönen M, et al. Survival after hepatic resection for metastatic colorectal cancer: trends in outcomes for 1,600 patients during two decades at a single institution. J Am Coll Surg 2010;210:744-52, 752-5.

39. Choti MA, Sitzmann JV, Tiburi MF, et al. Trends in long-term survival following liver resection for hepatic colorectal metastases. Ann Surg 2002;235:759-66.

40. Cherqui D, Husson E, Hammoud R, et al. Laparoscopic liver resections: a feasibility study in 30 patients. Ann Surg 2000;232:753-62.

41. Allard MA, Cunha AS, Gayet B, et al. Early and Longterm Oncological Outcomes After Laparoscopic Resection for Colorectal Liver Metastases: A Propensity Score-based Analysis. Ann Surg 2015;262:794-802.

42. Gold JS, Are C, Kornprat P, et al. Increased use of parenchymal-sparing surgery for bilateral liver metastases from colorectal cancer is associated with improved mortality without change in oncologic outcome: trends in treatment over time in 440 patients. Ann Surg 2008;247:109-17.

43. Elias D, Desruennes E, Lasser P. Prolonged intermittent clamping of the portal triad during hepatectomy. Br J Surg 1991;78:42-4.

44. Wu CC, Hwang CR, Liu TJ, et al. Effects and limitations of prolonged intermittent ischaemia for hepatic resection

Cite this article as: Untereiner X, Cagniet A, Memeo R, Tzedakis S, Piardi T, Severac F, Mutter D, Kianmanesh R, Marescaux J, Sommacale D, Pessaux P. Laparoscopic hepatectomy versus open hepatectomy for colorectal cancer liver metastases: comparative study with propensity score matching. HepatoBiliary Surg Nutr 2016;5(4):290-299. doi: 10.21037/ hbsn.2015.12.06 of the cirrhotic liver. Br J Surg 1996;83:121-4.

45. Belghiti J, Noun R, Malafosse R, et al. Continuous versus intermittent portal triad clamping for liver resection: a controlled study. Ann Surg 1999;229:369-75.

46. De Carlis L, Di Sandro S, Giacomoni A, et al. Colorectal liver metastases: hepatic pedicle clamping during hepatectomy reduces the incidence of tumor recurrence in selected patients. Case-matched analysis. Eur J Surg Oncol 2013;39:726-33.

47. Cannon RM, Scoggins CR, Callender GG, et al. Laparoscopic versus open resection of hepatic colorectal metastases. Surgery 2012;152:567-73; discussion 573-4.

48. Dagher I, Proske JM, Carloni A, et al. Laparoscopic liver resection: results for 70 patients. Surg Endosc 2007;21:619-24.

49. Topal B, Fieuws S, Aerts R, et al. Laparoscopic versus open liver resection of hepatic neoplasms: comparative analysis of short-term results. Surg Endosc 2008;22:2208-13.

50. Mala T, Edwin B, Rosseland AR, et al. Laparoscopic liver resection: experience of 53 procedures at a single center. J Hepatobiliary Pancreat Surg 2005;12:298-303.

51. D'Agostino RB Jr. Propensity score methods for bias reduction in the comparison of a treatment to a nonrandomized control group. Stat Med 1998;17:2265-81.

52. Austin PC. Statistical criteria for selecting the optimal number of untreated subjects matched to each treated subject when using many-to-one matching on the propensity score. Am J Epidemiol 2010;172:1092-7.

53. Guo S, Fraser MW. Propensity score analysis: Statistical methods and applications. Sage Publications, 2014;11.

54. Abu Hilal M, Underwood T, Zuccaro M, et al. Short- and medium-term results of totally laparoscopic resection for colorectal liver metastases. Br J Surg 2010;97:927-33.

55. Castaing D, Vibert E, Ricca L, et al. Oncologic results of laparoscopic versus open hepatectomy for colorectal liver metastases in two specialized centers. Ann Surg 2009;250:849-55. 